\title{
TSHRV656F Activating Variant of the Thyroid Stimulating Hormone Receptor Gene in Neonatal Onset Hyperthyroidism: A Case Review
}

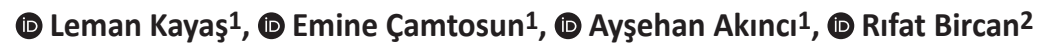 \\ 1Inönü University Faculty of Medicine, Department of Pediatric Endocrinology, Malatya, Turkey \\ 2 Tekirdağ Namık Kemal University, Faculty of Science and Literature, Department of Molecular Biology and Genetics, Tekirdağ, Turkey
}

\begin{abstract}
What is already known on this topic?
Neonatal hyperthyroidism is a rare condition and is most frequently caused by the transplacental transmission of thyroid receptor stimulating antibodies from a mother with Graves' disease. Activating variants of the TSHR gene are rare causes of neonatal hyperthyroidism, which play a significant role in the etiology of familial (autosomal dominant) and sporadic non-autoimmune hyperthyroidism (NAH).
\end{abstract}

\section{What this study adds?}

We present a case of neonatal onset congenital NAH with a sporadic germline activating V656F variant in the TSHR gene. This variant was described in the literature as a somatic variant in children and adults with toxic thyroid nodule(s) that resulted in the structural activation of the TSH receptor. This study is the first case to highlight the relationship between this variant and neonatal onset NAH.

\begin{abstract}
An activating variant of the thyroid stimulating hormone receptor (TSHR) gene is one of the rare causes of neonatal hyperthyroidism. This disorder may occur as a result of an autosomal dominant inheritance or sporadically through de novo variation. Here we present a case of neonatal onset congenital non-autoimmune hyperthyroidism (NAH) with a sporadic germline activating TSHRV656F variant. A female infant with tachycardia, who was transferred due to hyperthyroidism in the first week of life, displayed no other symptoms or signs. The patient's mother did not have Graves' disease, and TSHR stimulating antibodies were not present in the mother or baby. Imaging showed thyroid gland hyperplasia and left ventricular hypertrophy, the patient was subsequently put on methimazole treatment. After six months undergoing treatment, a heterozygous p.Val656Phe (V656F) (c.1966G > T) variant was detected on exon 10 of the TSHR gene. The variant was not identified in the mother and father, so the case was assumed to be sporadic. In conclusion, although the literature describes V656F variant as a somatic variant in children and adults with toxic thyroid nodule(s) that results in the structural activation of the TSH receptor, no previous cases of neonatal hyperthyroidism due to TSHRV656F variant have been reported. This study is the first case review that highlights the relationship between TSHRV656F variant and neonatal onset NAH.
\end{abstract}

Keywords: Neonatal hyperthyroidism, activating variant of TSHR gene, non-autoimmune hyperthyroidism

\section{Introduction}

Hyperthyroidism in children is a rare, heterogeneous condition characterized by an excessive production of thyroid hormone (1). Approximately $1 \%$ of childhood thyrotoxicosis cases emerge in the neonatal period. Neonatal hyperthyroidism, which has an estimated prevalence of $1 / 50,000$, is primarily caused by temporary hyperthyroidism due to maternal Graves' disease and is characterized by the presence of thyroid receptor stimulating antibodies (TRsAB) that have been passed on to the newborn by the mother $(2,3)$. Autoimmune congenital hyperthyroidism continues for nearly four months following birth and is alleviated when the maternal TRSAB is gradually eliminated from the infant's blood (3). Persistent neonatal cases of hyperthyroidism in which no antibodies are detected may be related to 
less common, non-autoimmune genetic etiologies, such as activating variants in the thyroid stimulating hormone receptor (TSHR) gene, somatic activating variants of the GNAS gene which encodes the stimulant alpha sub-unit of the guanine nucleotide binding protein as is the case in McCune-Albright syndrome (MAS), and less frequently through variants in the thyroid receptor $\beta$ gene $(3,4)$. MAS is an uncommon etiology of neonatal hyperthyroidism, and is characterized by additional findings, including cafe au lait macules on the skin, skeletal deformities caused by fibrous dysplasia, and signs associated with hormonal hyperfunction such as Cushing syndrome and/or peripheral precocious puberty (5). In the literature, there have been case reports of individuals diagnosed with thyroid hormone resistance due to variants in the thyroid receptor $\beta$ gene, leading to symptoms of neonatal hyperthyroidism. However, unlike the others, suppression of serum TSH was not observed in these patients $(6,7)$.

In the literature, activating TSHR gene variants have been frequently reported in the genetic analysis of children and adults with toxic thyroid nodule(s) $(8,9,10,11)$, and less commonly in cases of neonatal hyperthyroidism $(12,13)$.

In this study, we present a case of neonatal onset, congenital, non-autoimmune hyperthyroidism (NAH) with a sporadic germline activating TSHRV656F variant, and whose family history is negative for NAH.

\section{Case Report}

A female patient, the third live born from the fourth pregnancy of a 27-years-old mother, was born at term through normal vaginal birth, weighing $3110 \mathrm{~g}$. The patient exhibited tachycardia on the third day. The patient's family history was negative for thyroid disease. However, the mother was observed to have goiter during evaluation. Physical examination revealed body weight to be $3600 \mathrm{~g}$ (50-75p), height $48 \mathrm{~cm}$ (10-25p), head circumference 35 cm (25-50p), rhythmic heart rate 160-170/min. Other than mild tachycardia, no signs of pathology were observed and cafe au lait macules were not present on the skin. Laboratory tests revealed a free thyroxine (fT4) level of 3.41 ng/dL (0.93-1.7), and thyroid stimulating hormone (TSH) level of $0.005 \mathrm{mIU} / \mathrm{mL}(0.35-4.94)$. Laboratory analysis at seven days of age showed the serum level of free triiodothyronine (fT3) as $12.54 \mathrm{pg} / \mathrm{mL}(1.8-4.6)$, fT4 level $3.22 \mathrm{ng} / \mathrm{dL}(0.83-1.76)$, and TSH level $<0.01 \mathrm{mIU} / \mathrm{L}(1.78-$ 12.6) consistent with hyperthyroidism. While serum antithyroid peroxidase (anti-TPO) antibody was positive, antithyroglobulin (anti-TG) and TSH receptor antibodies (TRAB) were not detected. Thyroid ultrasonography (USG) revealed diffuse hyperplasia of the thyroid gland. Echocardiogram showed mild hypertrophy of the left ventricle. The thyroid function tests of the mother were reported as euthyroid with anti-TPO $[60 \mathrm{IU} / \mathrm{mL}(<35)]$ and anti-TG $[79.3 \mathrm{IU} / \mathrm{mL}$ $(<40)]$ antibodies being detected in the serum, TRAB $[0.3$ IU/L (0-1.75)] was not.

At seven days of age, the patient was put on treatment with $0.5 \mathrm{mg} / \mathrm{kg} /$ day methimazole (in two doses) and $2 \mathrm{mg} / \mathrm{kg} / \mathrm{day}$ propranolol (in two doses). On the eighth day of treatment, methimazole treatment was reduced and eventually discontinued due to low fT4 levels. However, on the fifth day following medical discontinuation, thyroid function tests revealed hyperthyroidism and the patient was put back on methimazole. Based on the results of thyroid function tests, the dose of treatment was adjusted between 0.15-0.75 $\mathrm{mg} / \mathrm{kg} / \mathrm{day}$, and the patient maintained a euthyroid state. Propranolol treatment was discontinued as the patient's tachycardia had resolved.

The patient had tested negative for TRAB from the onset of disease, anti-TPO antibodies had receded, and the patient required more than six months of anti-thyroid treatment. For these reasons, a prediagnosis of NAH was considered. The patient did not demonstrate any additional signs of MAS, and a p.Val656Phe (c.1966G > T) heterozygous variant was detected on exon 10 of the TSHR gene. The case was confirmed to be sporadic as the same variant was not detected in the mother and father (Figure 1).

During follow-up of methimazole treatment, the patient's physical examination showed normal sized thyroid glands, normal growth and development, and two periodic thyroid USG evaluations were reported as normal. During the last assessment at 25 months of chronological age, the patient's height was $85 \mathrm{~cm}$ (10-25p), which was consistent with her genetic target height, and body weight was $11.1 \mathrm{~kg}$ (10-25p). Neuromotor development was appropriate for chronological age. At the time of writing, the patient continues with methimazole treatment $(0.45 \mathrm{mg} / \mathrm{kg} /$ day $)$ and maintains a euthyroid state.

\section{Discussion}

Here, we present a case of neonatal onset congenital $\mathrm{NAH}$ with a sporadic germline activating TSHRV656F variant. When hyperthyroidism is detected in a newborn, autoimmune causes must initially be considered and the baby as well as the mother should be assessed for TRsAB. If no autoimmune reasons can be identified in persistent cases of neonatal hyperthyroidism, genetic etiologies should be considered (3). 
Since our patient had a persistent NAH and there were no additional findings suggestive of MAS, genetic analysis was conducted initially for TSHR activating variants, and a heterozygous sporadic activating V656F (Val656Phe) variant was detected on the TSHR gene. Activating germline variants of the TSHR gene that display an autosomal dominant inheritance pattern lead to familial or hereditary NAH (FNAH). In contrast, de novo variants lead to sporadic $\mathrm{NAH}$ (SNAH), as is the case in our patient. Although uncommon, somatic variants of the TSHR gene can also lead to autonomic thyroid adenomas in children (14).

Data in the literature regarding activating TSHR variants and their clinical characteristics are accessible on a periodically updated database, started in 1999 (15). In the literature, there are a few case reports of SNAH in which symptoms were present during the neonatal period $(12,13)$. The variant detected in our case was first reported in 1997 by Führer et al (8) in a patient with toxic thyroid nodule. Wonerow et al (9) confirmed this variant to be an activating point variant of the TSHR gene. In

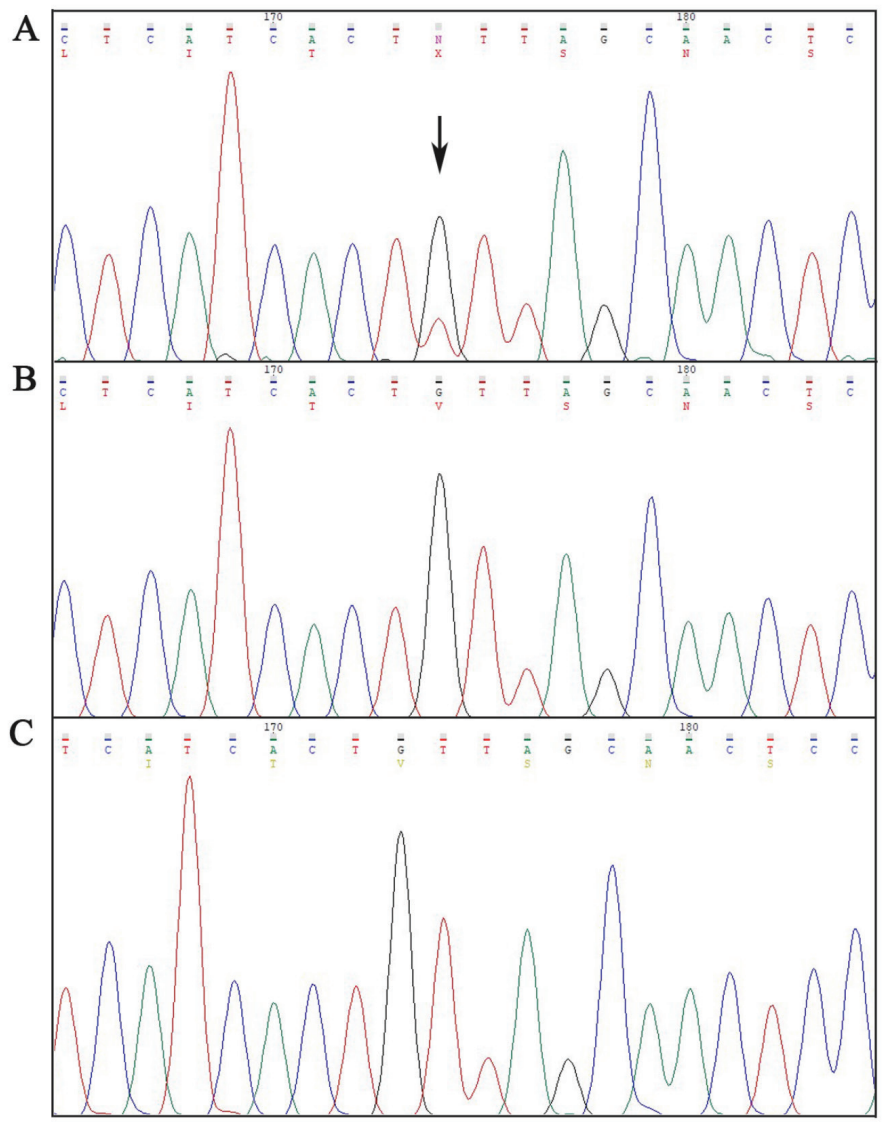

Figure 1. A) The index patient's DNA sample showing a Val656Phe (gtt $\rightarrow \mathrm{ttt}$ ) missense mutation on exon 10 of the TSHR gene. B) The corresponding TSHR gene region sequence of the mother (wild type). C) The corresponding TSHR gene region sequence of the father (wild type) subsequent years, this variant was observed in some child and adult patients with toxic thyroid nodule(s) $(8,9,10,11,16,17)$. However, after a thorough review of the literature, we did not find any reports of the variant in neonatal cases of hyperthyroidism. In comparison to FNAH, cases of SNAH tend to show symptoms at an earlier age and exhibit more severe clinical manifestations. However, the signs may be affected by genetic, epigenetic, and environmental factors as well as the in vitro activity of TSHR gene variants. Akcurin et al (18) reported three cases of the same variant from the same family in which FNAH emerged at different ages. One of the siblings had symptoms during infancy and was diagnosed with hyperthyroidism at age 3.5 years, the other was diagnosed at 12 days old, and their father was diagnosed with toxic multinoduler goiter at 36 years old. Thus, the phenotype-genotype relationship of the disease appears not to be clear.

Congenital NAH can show clinical signs even in the fetus, which may include tachycardia, arrhythmia, intrauterine growth restriction, and premature birth (12). Our patient was born at term with a normal birth weight. In the first week of the neonatal period, tachycardia was observed in the patient's physical examination. Imaging displayed signs of potential intrauterine involvement, including diffuse hyperplasia of the thyroid gland and mild left ventricular hypertrophy. After the neonatal period, NAH can manifest in babies as tachycardia, growth retardation, accelerated linear growth, advanced bone age, craniosynostosis, restlessness and/or delay in development (14). In our case, these manifestations were prevented in infancy by ensuring a euthyroid state through appropriate management with anti-thyroid medication (ATM). NAH typically causes diffuse enlarged goiter in childhood, and progresses to multinodular goiter at older ages. An important diagnostic criterion for NAH is absence of ophthalmopathy. Unlike Graves' disease, serological testing shows no anti-thyrotropin receptor antibodies, and histopathological examination of thyroid tissue does not show the characteristic mononuclear cell infiltration of Graves' disease; autoimmune markers are not observed during immunohistological analysis (19).

The treatment for hereditary and persistent SNAH differs from that of autoimmune hyperthyroidism in which ATM is temporarily (3-4 months) used (3). Congenital NAH that is caused by activating variants of the TSHR gene presents with persistent and severe manifestations of hyperthyroidism. For this reason, ATM may be initially used, but curative approaches, such as surgery or radioactive iodine (RAI) ablation are required (20). Otherwise, the patient 
may experience relapses of hyperthyroidism following discontinuation of ATM. Relapses may even be observed in cases of incomplete ablation (subtotal thyroidectomy or a RAI dose that is non-ablative). Remission is observed in nearly $50 \%$ of patients one year after ATM. In SNAH, the recovery time of the pituitary-thyroid feedback axis cannot be predicted, and TSH may remain suppressed for more than one year following birth. Due to the rarity of FNAH and SNAH, well-characterized case series have presented valuable information regarding the best treatment methods and various therapeutic modalities. In our case, euthyroidism was quickly attained through ATM, and curative treatment was planned for the future.

\section{Conclusion}

We have reported the first case of neonatal hyperthyroidism associated with a sporadic activating V656F variant of the TSHR gene. Sporadic, de novo, activating variants in the TSHR gene can cause severe hyperthyroidism in the neonatal period. As in our case, in patients who present with persistent NAH with early onset diffuse goiter, and who have no family history or additional systemic involvement, sporadic activating TSHR gene variants should be considered and genetic analysis should be planned. Genetic diagnosis is also a guide for treatment because curative treatment is ultimately required during follow-up in these patients.

\section{Ethics}

Informed Consent: Consent form was filled out by the parents of the patient.

Peer-review: Externally peer-reviewed.

\section{Authorship Contributions}

Surgical and Medical Practices: Leman Kayaş, Emine Çamtosun, Ayşehan Akıncı, Concept: Leman Kayaş, Emine Çamtosun, Ayşehan Akıncı, Designn: Leman Kayaş, Emine Çamtosun, Ayşehan Akıncı, Data Collection or Processing: Leman Kayaş, Emine Çamtosun, Analysis or Interpretation: Leman Kayaş, Emine Çamtosun, Ayşehan Akıncı, Rıfat Bircan, Literature Search: Leman Kayaş, Emine Çamtosun, Writing: Leman Kayaş, Emine Çamtosun, Ayşehan Akıncı, Rifat Bircan.

Financial Disclosure: The authors declared that this study received no financial support.

\section{References}

1. Léger J, Carel JC. Diagnosis and management of hyperthyroidism from prenatal life to adolescence. Best Pract Res Clin Endocrinol Metab 2018;32:373-386. Epub 2018 Apr 5
2. Polak M, Legac I, Vuillard E, Guibourdenche J, Castanet M, Luton D. Congenital hyperthyroidism: the fetus as a patient. Horm Res 2006;65:235-242. Epub 2006 Mar 30

3. Kurtoğlu S, Özdemir A. Fetal neonatal hyperthyroidism: diagnostic and therapeutic approachment. Turk Pediatri Ars 2017;52:1-9.

4. Segni M. Neonatal Hyperthyroidism. In: Feingold KR, Anawalt B, Boyce A (eds). Endotext. South Dartmouth (MA): MDText.com, Inc. 2019.

5. Lourenço R, Dias P, Gouveia R, Sousa AB, Oliveira G. Neonatal McCuneAlbright syndrome with systemic involvement: a case report. J Med Case Rep 2015;9:189.

6. Blair JC, Mohan U, Larcher VF, Rajanayagam O, Burrin JM, Perry LA, Grossman AB, Chatterjee VK, Savage MO. Neonatal thyrotoxicosis and maternal infertility in thyroid hormone resistance due to a mutation in the TRbeta gene (M313T). Clin Endocrinol (Oxf) 2002;57:405-409.

7. Yatsuga S, Hiromatsu Y, Sasaki S, Nakamura H, Katayama K, Nishioka J, Koga Y. A two-day-old hyperthyroid neonate with thyroid hormone resistance born to a mother with well-controlled Graves' disease: a case report. J Med Case Rep 2012;6:246.

8. Führer D, Holzapfel HP, Wonerow P, Scherbaum WA, Paschke R. Somatic mutations in the thyrotropin receptor gene and not in the Gs alpha protein gene in 31 toxic thyroid nodules. J Clin Endocrinol Metab 1997;82:3885-3891.

9. Wonerow P, Chey S, Führer D, Holzapfel HP, Paschke R. Functional characterization of five constitutively activating thyrotrophin receptor mutations. Clin Endocrinol (Oxf) 2000;53:461-468.

10. Trülzsch B, Krohn K, Wonerow P, Chey S, Holzapfel HP, Ackermann F, Führer D, Paschke R. Detection of thyroid-stimulating hormone receptor and Gsalpha mutations: in 75 toxic thyroid nodules by denaturing gradient gel electrophoresis. J Mol Med (Berl) 2001;78:684691.

11. Palos-Paz F, Perez-Guerra O, Cameselle-Teijeiro J, Rueda-Chimeno C, Barreiro-Morandeira F, Lado-Abeal J; Galician Group for the Study of Toxic Multinodular Goitre, Araujo Vilar D, Argueso R, Barca O, Botana M, Cabezas-Agrícola JM, Catalina P, Dominguez Gerpe L, Fernandez T, Mato A, Nuño A, Penin M, Victoria B. Eur J Endocrinol 2008;159:623631. Epub 2008 Aug 11

12. Cho WK, Ahn MB, Jang W, Chae H, Kim M, Suh BK. Nonautoimmune congenital hyperthyroidism due to p.Asp633Glu mutation in the TSHR gene. Ann Pediatr Endocrinol Metab 2018;23:235-239. Epub 2018 Dec 31

13. Aycan Z, Ağladıoğlu SY, Ceylaner S, Cetinkaya S, Baş VN, Kendirici HN. Sporadic nonautoimmune neonatal hyperthyroidism due to A623V germline mutation in the thyrotropin receptor gene. J Clin Res Pediatr Endocrinol 2010;2:168-172. Epub 2010 Nov 7

14. Roberts SA, Moon JE, Dauber A, Smith JR. Novel germline mutation (Leu512Met) in the thyrotropin receptor gene (TSHR) leading to sporadic non-autoimmune hyperthyroidism. J Pediatr Endocrinol Metab 2017;30:343-347.

15. Welcome to the Thyroid Stimulating Hormone Receptor (TSHR) Mutation Database. Last Accessed Date: January 2022. Available from: https://www.tsh-receptor-mutation-database.org

16. Eszlinger M, Niedziela M, Typlt E, Jaeschke H, Huth S, Schaarschmidt J, Aigner T, Trejster E, Krohn K, Bösenberg E, Paschke R. Somatic mutations in 33 benign and malignant hot thyroid nodules in children and adolescents. Mol Cell Endocrinol 2014;393:39-45. Epub 2014 Jun 8

17. Gozu HI, Bircan R, Krohn K, Müller S, Vural S, Gezen C, Sargin H, Yavuzer D, Sargin M, Cirakoglu B, Paschke R. Similar prevalence of somatic TSH receptor and Gsalpha mutations in toxic thyroid nodules in geographical regions with different iodine supply in Turkey. Eur J Endocrinol 2006;155:535-545. 
18. Akcurin S, Turkkahraman D, Tysoe C, Ellard S, De Leener A, Vassart G, Costagliola S. A family with a novel TSH receptor activating germline mutation (p.Ala485Val). Eur J Pediatr 2008;167:1231-1237. Epub 2008 Jan 4

19. Gönç EN, AlikaşifoğluA. Hyperthyroidism. In: Cinaz P, Darendeliler F, Akıncı A, Özkan B, Dündar BN, Ayhan A (eds). Pediatric Endocrinology. İstanbul, Nobel Kitabevi, 2014:335-345.
20. Ferraz C, Paschke R. Inheritable and sporadic non-autoimmune hyperthyroidism. Best Pract Res Clin Endocrinol Metab 2017;31:265275. Epub 2017 Apr 22 